\title{
ERP SYSTEM FOR COLLEGE AUTOMATION USING RFID TAGS
}

\author{
Bharti Chauhan $^{1}$, Amritha Balachandran ${ }^{2}$, Umesh Chauhan $^{3}$, Ashish Bokare ${ }^{4}$ \\ ${ }^{1}$ BE, Department of Computer Engineering, Imperial College of Engineering and Research, Maharashtra, India \\ ${ }^{2}$ BE, Department of Computer Engineering, Imperial College of Engineering and Research, Maharashtra, India \\ ${ }^{3}$ BE, Department of Computer Engineering, Imperial College of Engineering and Research, Maharashtra, India \\ ${ }^{4}$ BE, Department of Computer Engineering, Imperial College of Engineering and Research, Maharashtra, India
}

\begin{abstract}
Enterprise resource planning system is a tool that is use by almost all the industries today because of its power to integrate multiple domain and fractions of work together. An industry may comprise of marketing, sales, quality assurance, human resource etc. The ERP system atomizes most of the manual work done internally in each of these divisions and it also combines the overall work out-put, this way it helps get a good overall view of the entire organization. The same quality of the ERP system is employed in the education sector which also consists of multiple fractions that need integration. For a very long time the paper work in the education sector has been a problem and this is because it is easy to make mistakes when the work is done manually. Human error is inevitable and since human mind has a volatile memory and cannot store too much data there is a need for a system in place that can track and record all the events. This paper is about implementing an ERP system for college automation using RFID tags. Usage of RFID(radio frequency identification) tag helps in tagging each person with a unique ID and this is used for automated attendance marking.

This system consists of a set of integrated software modules that support the college in real time. Multiple modules are designed to support each fraction in the college starting from director level to student level. Implementation of this system leads to no paper work and no inconstancy in the data. It provides multiple benefits to the management, teachers and the students. this is a low cost system in terms of implementation and maintenance .
\end{abstract}

Keywords: RFID (radio frequency identification), Multiple modules, Enterprise resource planning (ERP).

\section{INTRODUCTION}

In today's world of atomization, where everyone craves for a simple and easy life, it becomes necessary to develop a system which enables the students and teachers to simplify their way of working. An ERP system goes a long way in helping the students and teachers to atomization each and every work they have to deal with. During 1960s the first centralized computing systems were developed by most of the organizations and extra features were added to them in early 90 s as new modules and functionalities. However, introduction of ERP system in college was not appreciated in the beginning by most of the universities around the world. Certain US colleges introduced ERP system in the campus, which was later shut down due to certain loopholes mentioned below

1. Inability of the system to cope up with the predetermined functionalities

2. Higher budget and lower throughput

3. Higher maintenance and training cost

4. Not so user friendly

5. Incorrect working of the system

These loopholes were solved in the later version of ERP system by improvising the modules and the user interface. The interface was self explanatory and user friendly.

Our system has followed this path of improvisation along with atomization for attendance system which is the most hectic task for a teacher. This system has used RFID for marking up the attendance of students automatically and generating a report for every student. This has reduced the work load on teachers and made the system less prone to errors. Also the student teachers chat system for guidance and counselling is an add on to the system making the colleges more flexible and open. Modules like automatic report generation, event creator, chat system has helped and made these tedious tasks a lot more easier.

Since all the data in the system is kept on cloud, it becomes easy for all the modules to access the data and make the changes to the data. This makes the updating, addition and deletion of data easy. Also it is very easy to configure a cloud for a system and it is user friendly.

This system has a lot of scope in the future, as the modules will be added to the existing system and improvised functionalities will remove all the loopholes in the system. It will be very easy to estimate the capabilities with the business process and map the same on the ERP system.

\section{LITERATURE REVIEW}

\section{Problem 1:}

The problem with the traditional school management system was that the attendance system was manual and human interpretation was required to interpret the overall result of 
student. This became a tedious task when the number of students was increased. The teachers were supposed to record the attendance of each student and generate a report for the same.

\section{Solution:}

The solution to this problem is developed in our system by introducing the RFID system and integrating it with the system. Here, the attendance is automatically recorded when the students keep their TAG (ID) close to the reader. The report is generated automatically and without errors based upon the attendance record of each and every student.

\section{Problem 2:}

The networks previously used were not secure. The communication between staff members and student-teacher communication was not secured and was prone to attacks. This became a problem for confidential data to be transmitted over the network.

\section{Solution:}

This problem was solved using HTTPS which is an abbreviation for Hypertext Transmission Protocol Secured. This is an addition to the previously used HTTP protocol. It provides security to the communication network by adding the capabilities of SSL/TLS to standard HTTP communications. The main intention for HTTPS is to provide authentication of the visited website and to protect the privacy and integrity of exchanged data.

\section{Problem 3:}

Previously, the data were kept on a centralized computer and any other system which requires the data will have to send a request to the central system. However, this was a problem because if the central PC goes down, the whole data will be unavailable to other systems. Also this led to authentication problems. The amendments made to the data were also a problem as the updates to the data may or may not be available.

\section{Solution:}

Introduction of cloud in the system helped to resolve this problem. The whole data is kept on cloud and can be accessed from any system. No centralized system is used. So the problem of availability is solved and the data integrity is maintained throughout.

\section{Problem 4:}

Use of RFID led to the problems like double attendance in the class which was major drawback for the system. This also created the problem for teachers and management.

\section{Solution:}

The solution for this was to introduce the time for refreshing in the system. After the updation of one student in the system, the reader will take 5 seconds to refresh. So the student will have to wait for $5 \mathrm{sec}$ to mark the proxy of other student in the system.

\section{Problem5:}

Marking attendance for the particular lecture was also a problem. How would the system will know in which lecture the attendance is to be marked.

\section{Solution:}

Time slots are added to resolve this problem. Three slots are made which are according to the lecture timings for the respective college. Timing constraints are added to mark the attendance in that particular slot. Reports for the students are generated according to this slot wise attendance. System clocks are synchronized with the ERP system to compare the slot timings.

\section{IMPLEMENTATION}

\section{RFID}

The main aim of this project is to record the attendance of students using RFID tags. Student is provided with his/her authorized tag to swipe over the reader to record their attendance.

In classrooms, time is wasted in roll calls as it is done by hand. In this proposed system, authorized student is given an RFID tag. This tag contains an integrated inbuilt circuit that is used for processing and storing information through modulating and demodulating of the radio frequency signal that is being transmitted.

Thus, the data stored in this .Once the student places the card in front of the RFID card reader, it reads the data and verifies it with the data stored in the microcontroller from 8051 family. If the information i.e data matches, then it displays a message on the LCD confirming the entry of that student else displays a message denying the attendance.

The status of a student's attendance can be retrieved from this system by pressing the status button interfaced to the microcontroller. Hence, a lot of time is saved as all the students attendance is directly stored in the data base.

This is a plug and play RFID Reader USB. It can be used to read our $125 \mathrm{kHz}$ based RFID cards. Connecting the reader to the USB port and it creates a new COM Port on the computer. When a RFID card (TAGS) is brought near the Reader, the card's data is output using in ASCII through a simple USART interface. Since most programming languages allow access to COM ports, it is simple to write custom software programs to read RFID cards and process them as required. 


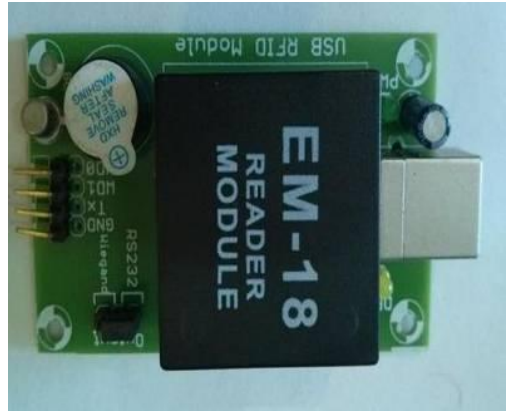

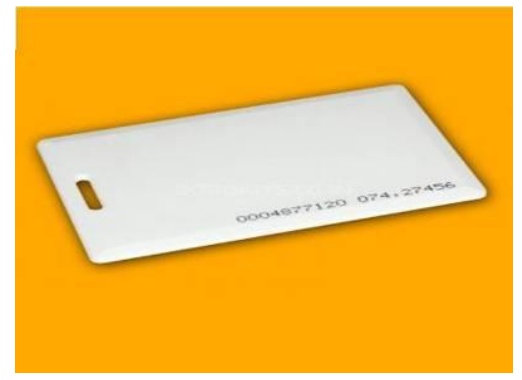

Fig -2 RFID TAG

Fig -1 RFID READER

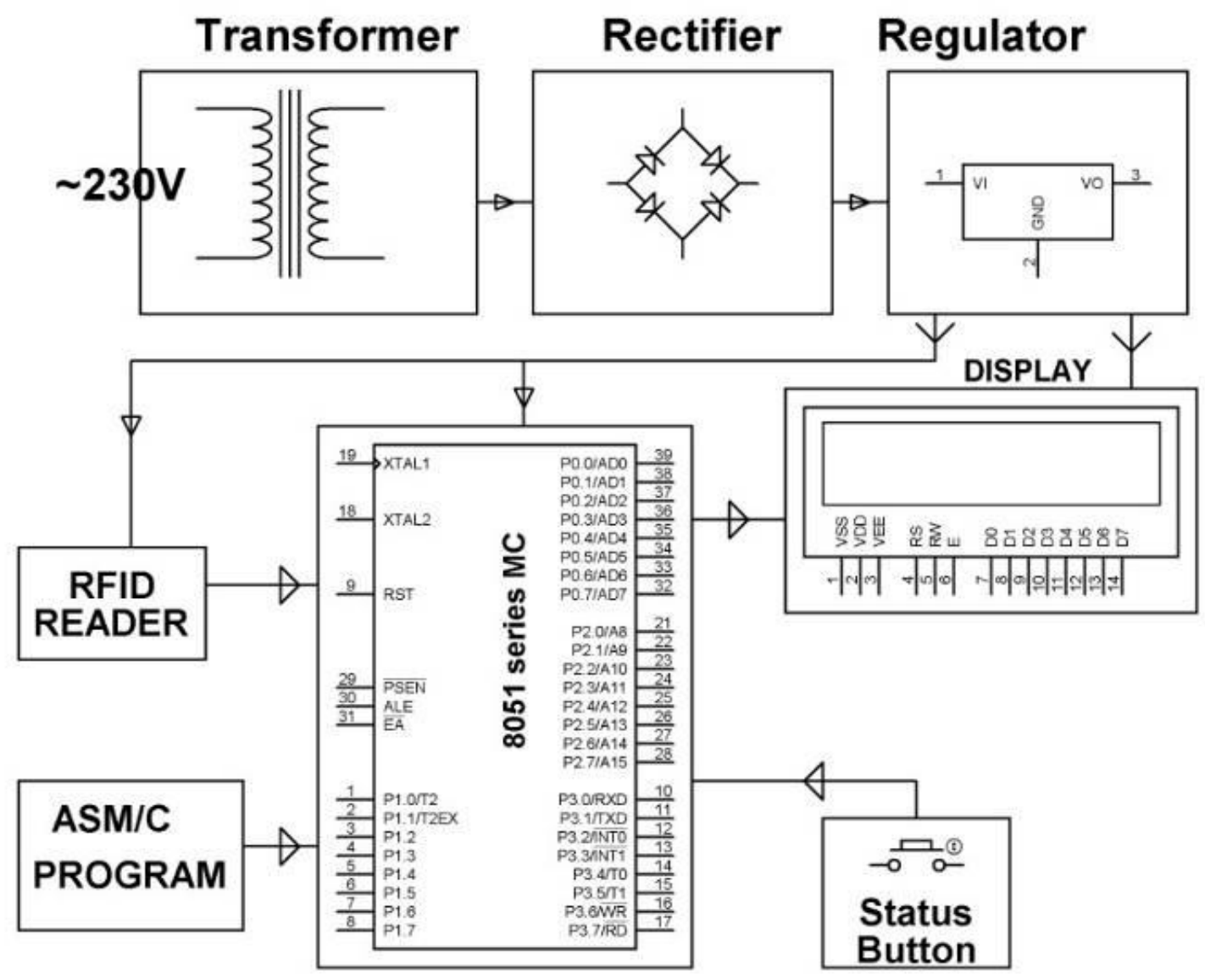

Fig -3 RFID based Attendance System Block Diagram

\section{PROPOSED ARCHITECTURE}

\subsection{Main Modules}

\section{Admission Module}

Students interested in taking adimission in the college can fill out a basic form online with name details and qualifications.after this a token is generated on the spot by the system which is valid only for 3 days and later becomes invalid. With in this 3 days time the student is expected to go physically to the college for document verification and take admission during which a permanent ID for student is generated.

\section{Students login(DONE AFTER ADMISSION)}

The permanent ID generated in the admission process is used by students for their login. After login the students can change password for security purpose.

\section{Student information}

This is how a student views his/her profile. Students can view their general, academic and fees and dues related information. Students can keep them self with the current events in college with the help of online notice board. this module mainly helps the students and parents track the progress of the student in college 
4. Teachers login(authenticated by principal)

Teachers create their own profile which is later approved by the department HOD . the teachers are expected to fill out their personal details this module helps teachers access functionalities like leave request, monitor assignments ,student details, monthly report generation and a teacher inbox for receiving mails.

\section{Staff HR module}

Get the college staff profiles which includes personal and official information under the staff HR module. Manage their salaries and leave requests online.

Evaluation of Reports generated by lower authorities

\section{Campus placement}

This module contains student list along with their achievements and qualifications which will be accessed by the Training and Placement officer.

Helps TnP officer to keep track of recent Drives and also helps in intimating students about it.

\section{College store}

ERP and would provide a dedicated buying channel for all the products and services such as laptop computers, software, college stationary etc.

Details of the retailer.

\section{Contact}

No of goods taken

Date of buying

Date of delivery

Price of goods

Mode of payment

Guarantee period

- Warrantee speriod

\section{Online Attendance}

- Attendance with the help of RFID CARDS.

- Updated in data base

- Teachers report generated

- Email sent to the students who are absent the very day.

- Monthly attendance report generated.

- Defaulters are fined.

9. Transport module

- Details of students coming via bus

- Amount paid

- Id card issue (buss pass)

○ bus no

- contact details

- class

o name

○ college name

- signature of transport officer

○ signature of principal

\subsection{Tabular Representation}

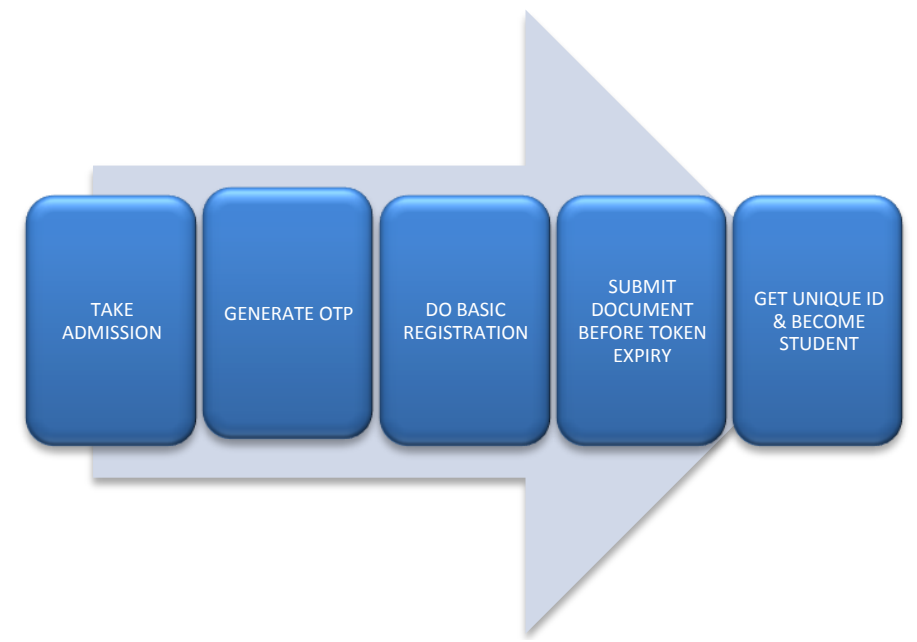

Fig -4 Admission Process

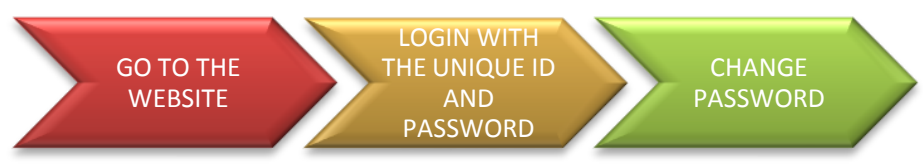

Fig -5 Student Access

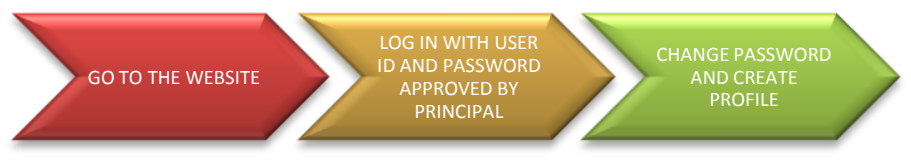

Fig -6 Teacher Access 


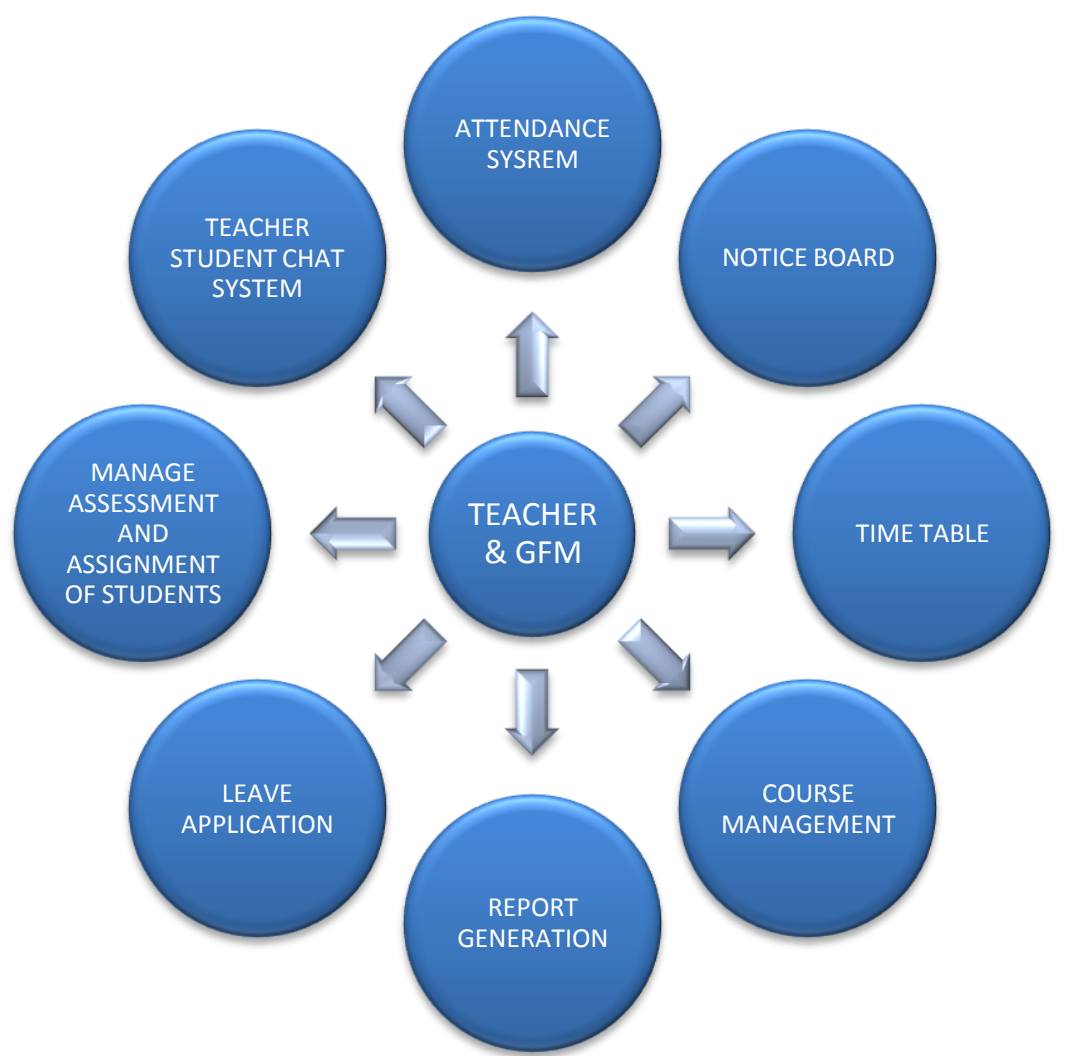

Fig -7 Functionalities Provided For Teachers

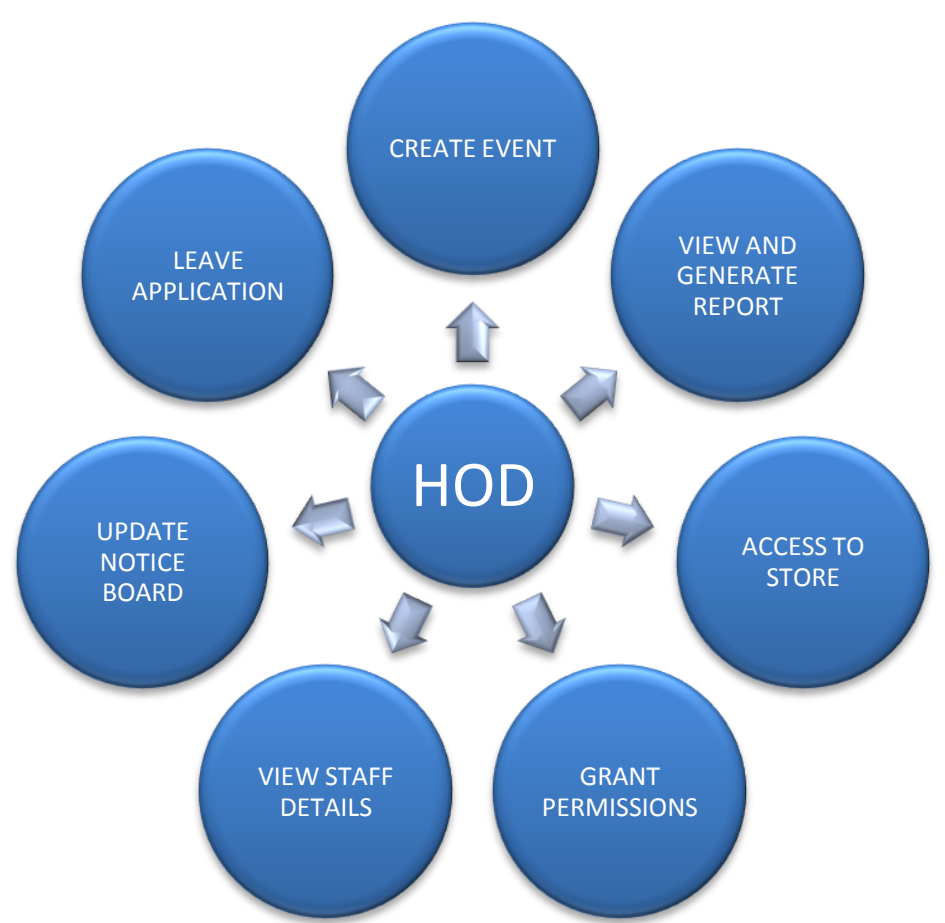

Fig -8 Functionalities Provided To Hod 


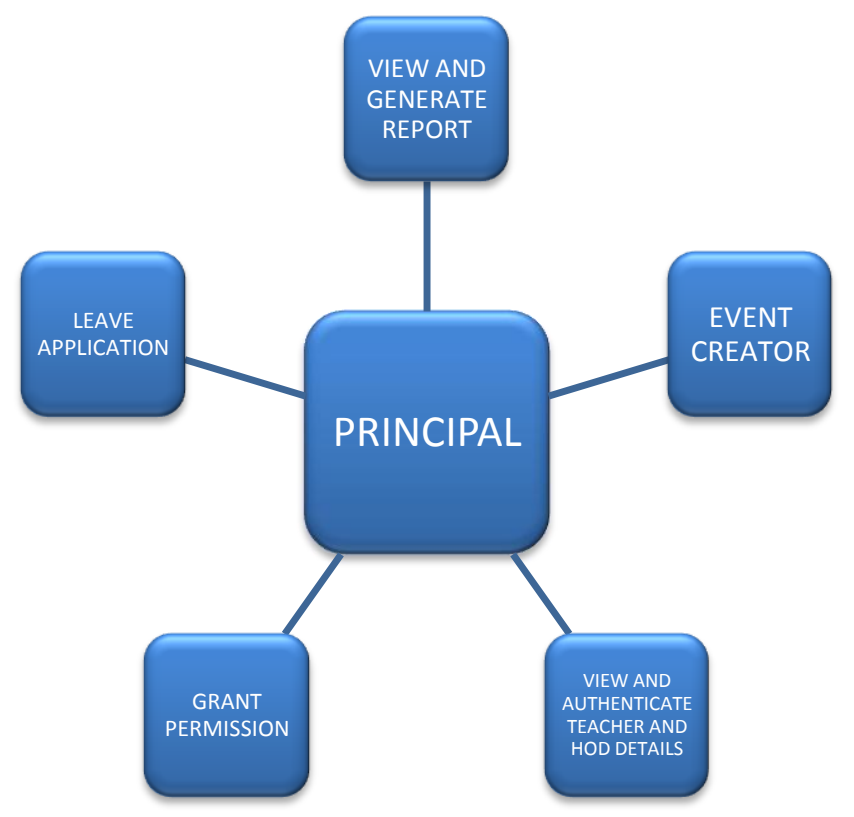

Fig -9 Functionalities Provided To Principal

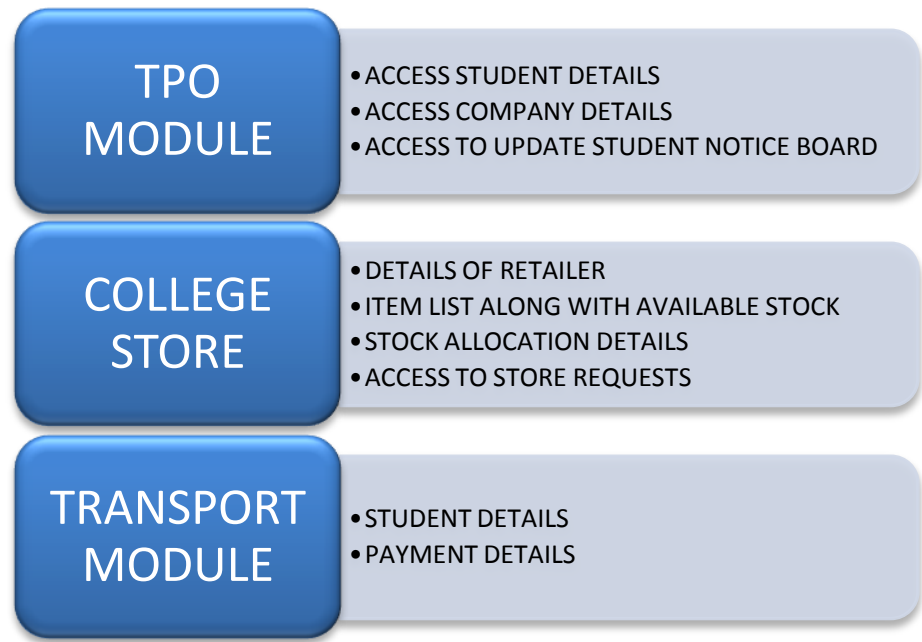

Fig -10 Standalone System Module 


\subsection{Screen Shots of Some Modules}

\section{College ERP}

Resize this responsive page to see the effect!

College ERP Home Admin Login Statt Login Student Login Enquy FeedBack

Do You Want Addmission

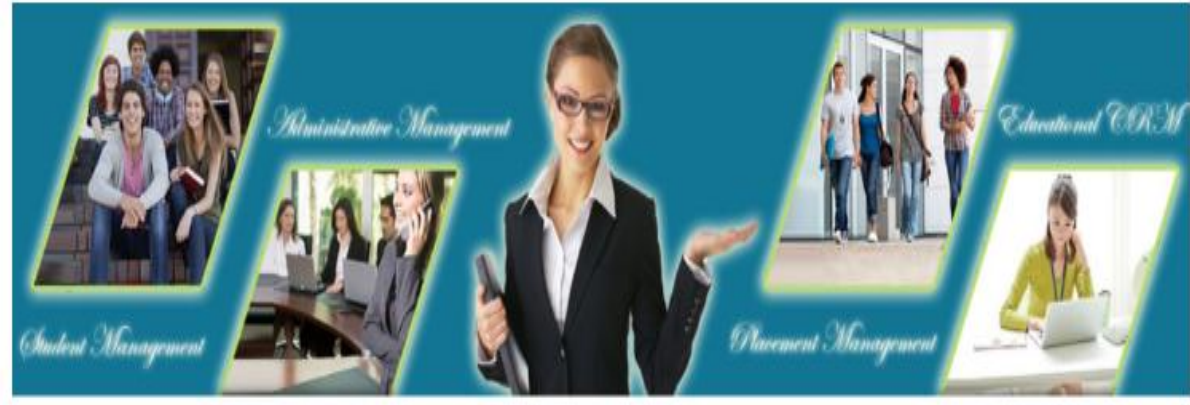

\section{Capmus Life}

From the modest beginning in 2001, JSPM, Pune has now groum into a fully integrated gisbal educational hub The Objectives of imparting education, combined with creation, dissemination and application of Knowledge are being met in an integrated form to create a synergetic impact at Five campuses of JSPM, namely.

\section{Courses we Provide}

was established in 1998 with the objective of creating centers of excellence for education in the feid of Engineering, Medical, Pharmacy, Management, computers etc. This is by the vision of Prof. TJ. Savant, an Electrical Engineer who thinks that, "Deveiopment of Techno - entrepreneurial society" is the key 10 achieve VISION 2020 as perceived by our Fomer PRESIDENT of India Dr Abdul Kalam.

\section{Awards \& Achievments}

was established in 1998 with the objective of crealing centers of excellence tor education in the feld of Engineering. Medical, Pharmacy, Management. computers etc. This is by the vision of Prof. T.J Sawant an Electical Engineer who thinks that, "Development of Techno - entrepreneurial society" is the key 10 achieve VISION 2020 as perceved by our Former PRESIDENT of Indla Dr Abdul Kalam.

\section{Fig -11 Home Screen}



Fig -12 Administration Login 


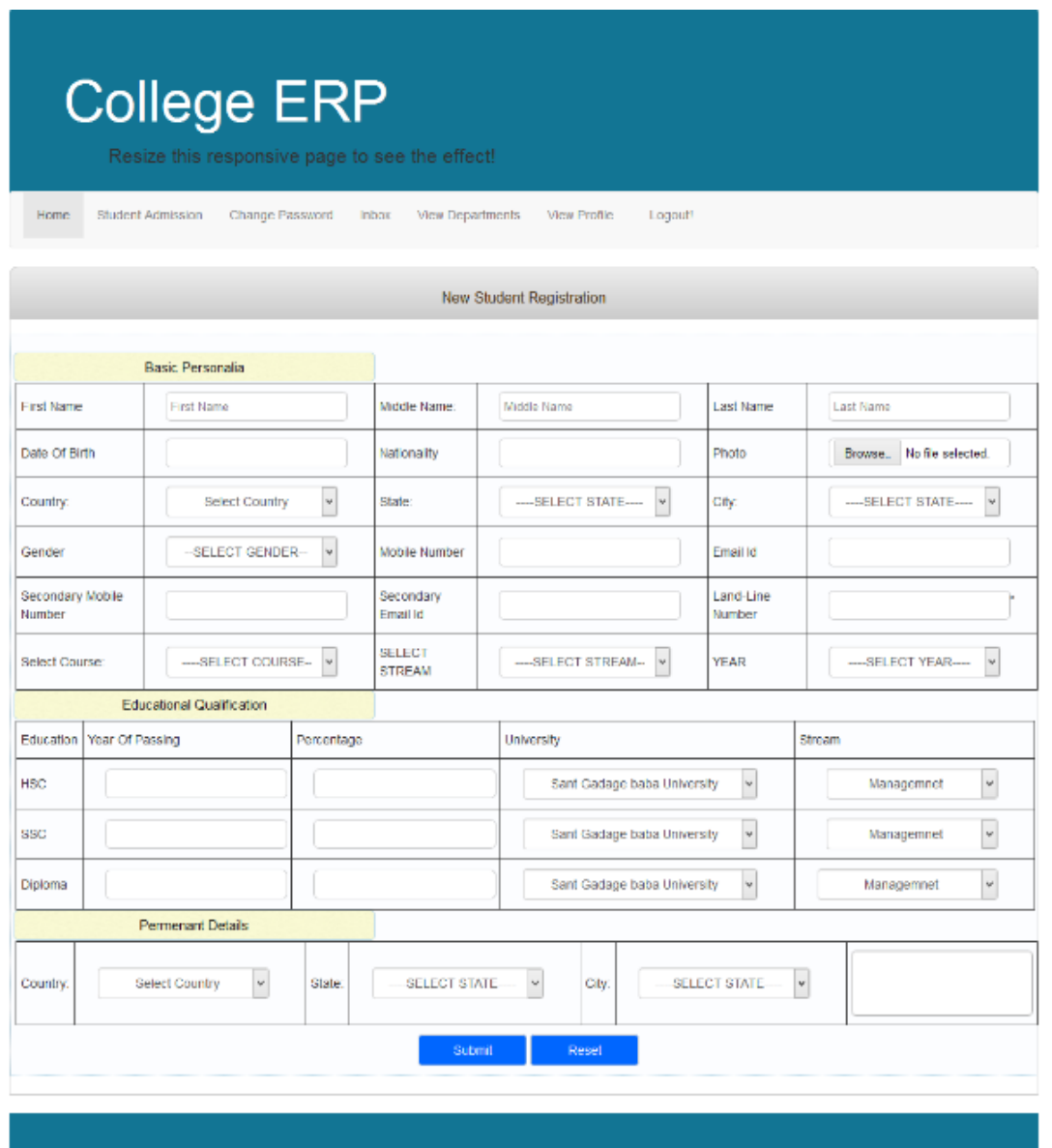

Fig -13 Admission Form

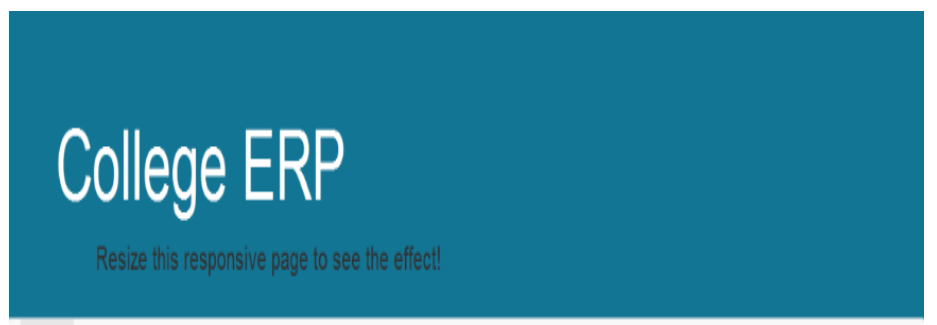

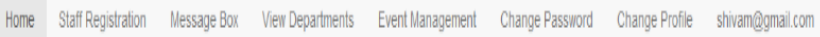

Event Management

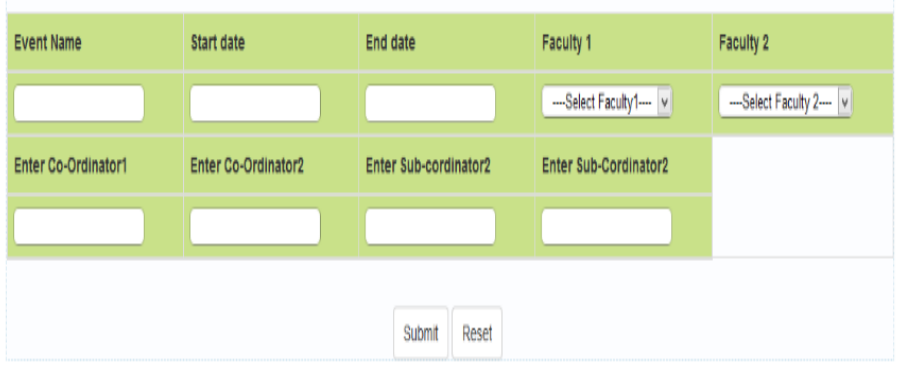

Fig -14 Event Creator Module 


\section{FUTURE SCOPE}

Make online exam more effective, efficient and more dynamic so that it helps to get a good support from the student. It has been marking while this application open in other browser due to designing support. It's more support to Mozilla as compare to other browser. Online result printing and more user interaction functionality and features need to be developed.

Needs to improve more security for the purpose of the safety. The project can be further enhanced by adding features like sending an SMS of the daily attendance of students to their parents. It can also be enhanced by using a smart card which can store comparatively higher amount of data and also card proximity can be checked in future to negate the double attendance problem in place of RFID module that has certain drawbacks of tags be misused.

\section{CONCLUSION}

In the ERP system, the RFID technology is used to collect the data about attendance conveniently. The real-time data acquisition and disposal largely enhances the efficiency of the operation of the attendance collection, and significantly enhance the efficiency of other modules in the system. The RFID application module in the system realizes the basic demand of enterprise to the ERP system, and the function modules with higher automation degree are implemented. The versatility of RFID is utilized in implementing a functional and automatic student attendance management system that allows students to simply mark their attendance just by swiping or moving their ID cards over the RFID reader. This system should change the way of student's attendance monitoring in the classroom and provide a new, accurate, and less cumbersome way of recording student's attendance. This technology offers reliability, saves time. In addition, a number of other advantages are gained by having an online web-based system, acting as a central repository of student attendance record. All processes of managing the student attendance record are performed online, allowing administrators and lecturers to view or modify the users' data through any computer via the web browser, as long as they are connected to the Internet. The captured student attendance data are also processed and analyzed automatically with less risk of data loss, compared to a manual filing approach. Cloud computing is beneficial for organization and individuals. There are also privacy and security concerns. If we are considering a cloud service, we should pay attention to protect our personal information

\section{ACKNOWLEDGEMENTS}

We would like to take this opportunity to thank a few who were closely involved in the completion of this endeavor. Through this acknowledgement, we express our sincere gratitude to all those people who have been associated with this paper and have helped us with it. We sincerely thank Dr. Sachin Admane, Principal of Imperial College of Engineering and Research, Prof. Satish Todmal, Head of Computer Department, Prof. Vinod Wadne, Guide who have cooperated with us at different stages during the preparation of the paper.

\section{REFERENCES}

[1]. Identifying the Missing Tags in a Large RFID System Tao Li Shigang Chen Computer \& Information Science \& Engineering University of Florida, Gainesville, FL, USA tali, sgchen\}@cise.ufl.eduYibei Ling Applied Research Laboratories Telcordia Technologies, NJ, USA lingy@ research.telcordia.com

[2]. Design and Application of the RFID Technology in ERP Juan Tian, Xiujuan Wang \&Lanhua ZhangCollege of Information Engineering, Taishan Medical University, Tai'an 271016, China

[3]. Research on RFID Integration Middleware for Enterprise Information SystemLi Minbo Software school, Fudan University, Shanghai, 201203, ChinaEmail: limb@fudan.edu.cn Li Hua Software school, Fudan University, Shanghai, 201203, ChinaEmail: 082053018@fudan.edu.cn

[4]. The Basics of Cloud Computing by Alexa Huth and James Cebula

\section{BIOGRAPHIES}



Bharti Chauhan, is a Final Year Graduate Student, pursuing her Bachelor of Engineering Degree in Computer Science at JSPM's Imperial College of Engineering and Research, Pune

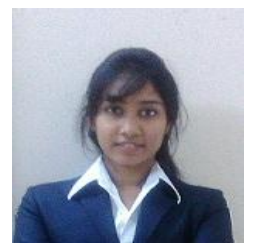

Amritha Balachandran Iyer, is a Final Year Graduate Student, pursuing her Bachelor of Engineering Degree in Computer Science at JSPM's Imperial College of Engineering and Research, Pune

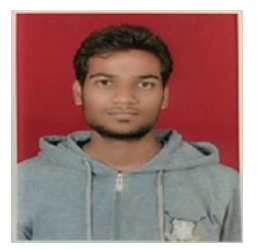

Umesh Chauhan, is a Final Year Graduate Student, pursuing his Bachelor of Engineering Degree in Computer Science at JSPM's Imperial College of Engineering and Research, Pune.

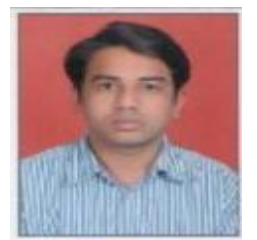

Ashish Bhokare, is a Final Year Graduate Student, pursuing his Bachelor of Engineering Degree in Computer Science at JSPM's Imperial College of Engineering and Research, Pune. 